\title{
CULTURA E DESENVOLVIMENTO: UMA ESTRATÉGIA DE ANALISE A PARTIR DE UM ESTUDO LONGITUDINAL DE FAMÍLIAS EM SALVADOR, BAHIA
}

\author{
CULTURE AND DEVELOPMENT: \\ AN ANALYSIS STRATEGY BASED ON A LONGITUDINAL STUDY \\ OF FAMILIES IN SALVADOR, BAHIA
}

\author{
Ana Cecilia de Souza Bastos ${ }^{1}$ \\ Célia Maria Lana da Costa Zannon ${ }^{2}$ \\ Miriã Alves Ramos de Alcântara ${ }^{3}$
}

BASTOS, A. C. d.; COSTA, C. M. L.d.; ALCÂNTARA, M. A. R. d. Cultura e desenvolvimento: uma estratégia de análise a partir de um estudo longitudinal de famílias em Salvador, Bahia. Rev. Bras. Cresc. Desenv. Hum., S. Paulo, 13(2): 20-34, 2003.

\begin{abstract}
Resumo: Este estudo foi conduzido com o objetivo de identificar alguns dos mecanismos cultur almente estruturados pelos quais a criança participa crescentemente da vida familiar e se tolda um membro co-responsável, ao desenvolver atividades ligadas à organização coletiva da vida cotidiana. Ent'atizou-se, além do contexto de interações no qual se promove essa inserção, as ideias pareníais sobre educação de filhos, tanto no plano mais genérico como no plano imediato da descrição da rotina familiar, justificando o engajamento da criança. Os valores culturais expressos pelas justificativas parentais, promovendo ou restringindo a participação da criança, são importantes dimensões do contexto desenvolvimental. As decisões tomadas ao longo deste trabalho foram orientadas por idéias de inspiração ecológica e semiótico-construtivistas e $\mathrm{c} \sim \mathrm{lt} \wedge \mathrm{l} \wedge$ ireinc ${ }^{\wedge} \mathrm{h} \wedge / . s i \sim e$. No plano empírico, essas questões conduziram a um estudo intensivo sobre dez famílias, ao longo de uma década. A analise, que assinala a interdependência entre contexto? idéias parentais e engajamento da criança, foi possível a partir da identificação da categoria $1770^{\wedge} \mathrm{dO} .5$ de partill ai; tomada como unidade de análise e extraída da análise das práticas culturais em curso no cotidiano familiar. Os modos de partilhar podem descrever, de um lado, os tipos, as qualidades e a natureza das relações entre idéias parentais e práticas de criação de filhos e, de outro, os valores culturais prevalentes no grupo cultural de referência. As análises efetuadas permitiram mostrar a interdependência entre as práticas educativas e o contexto cultura], que se r ealiza nas várias instâncias, interligados de uma maneira fluida, recíproca, não linear. Os modos de partilhar expressam a coordenação entre diferentes ordens de $\wedge^{\wedge}{ }^{\wedge} \mathrm{O} M{ }^{\wedge} \operatorname{straint}^{\wedge} \mathrm{s}$ externos e a ação dos cuidadores e da própria criança. Na conclusão, são discutidos dois exemplos dessa interdependência.
\end{abstract}

Palavras-chave: desenvolvimento-no-contexto; concepções parentais; participação infantil; "modos de partilhar".

\footnotetext{
1 Universidade Eederal da Bahia. Endereço para correspondência: Rua Macapá 461 - Ap. 60l. Ondina, Salvador, BA. CEP: 40150-170. E-mail: acecil@utba.hr

2 Universidadade Brasília. E-mail: zannon@unb.br

3 Universidadc Federal da Bahia E-mail: alcantaramiriam@hotmail.com
} 


\section{INTRODUÇÃO}

A construção de uma unidade de análise capaz de ser, ao mesmo tempo, abrangente e válida - focalizando o fenômeno psicológico de modo a atender a critérios de validade (medir o que se propõe medir, e não dimensões espúrias) tanto desenvolvimental e ecológica - tem sido uma preocupação explícita de muitos autores, como Urie BRONFENBRENNER e Jaan VALSINER. Pode também ser identificada em outros discursos correntes - a exemplo do movimento que se percebe no âmbito das representações sociais, ao se colocar em pauta a questão das práticas discursivas (SPINK, 1999; HARRÉ \& GILLET, 1994). É possível afirmar que a questão da unidade de análise legítima ou própria ao discurso psicológico, em particular na esfera do desenvolvimento, está no coração mesmo do discurso contemporâneo sobre a construção do conhecimento psicológico.

De início, repensa-se a natureza da explicação científica, de certa forma reduzida pela ordem positivista. Questiona-se a própria pretensão que aposta numa única ordem de explicação, a partir de uma descrição, predição e controle atendendo a requisitos de replicabilidade e prescrição. As palavras de AQUINO (1999) expressam bem um aspecto desse questionamento:

"Convenhamos que apostar em uma continuidade seqüencial, ordenada e progressiva no que tange às razões sobre os fatos e fenômenos que nos rodeiam, ou que se abrigam em nós, carreia uma função reguladora para a condição humana, protege-nos da angústia de reconhecer que não é possivel conhecer de fato aquilo que o futuro, sempre incerto, nos reserva" (p.12).

A explicação ou compreensão científica implica um movimento de mediação: da experiência pela teoria e da teoria pela experiência (SAMAJA, 1993). O desafio que se coloca é o de reconhecer a necessidade de transdução teoriaprática e ao mesmo tempo a "diferença”: a lógica do investigador não é necessariamente a mesma que a lógica dos fatos ${ }^{4}$. No estudo do desenvolvimento, torna-se necessário ainda esclarecer a natureza da descrição - ainda é necessário um esforço para distinguir os níveis descritivo e explanatório - remetendo, por exemplo, a resultados versus mecanismos, como fazem LIGHTFOOT e FOLDS-BENNETT (1992).
Para começar, é importante esclarecer que, na origem desta investigação, situam-se dois interesses: um temático e um teórico-metodológico. O primeiro é o estudo de processos através dos quais a criança realiza sua inserção em um mundo social. O segundo é o de construir uma unidade de análise adequada a esse objeto, perguntando-se: "como os niveis semântico e comportamental de um fenômeno ligado ao desenvolvimento podem ser integrados em uma mesma análise?” E, em decorrência: “Como selecionar a unidade de análise adequada a esse objetivo?”.

Da tentativa de apreender o contexto de desenvolvimento em sua dimensão processual, dinâmica, "viva", direciona-se o foco da descrição e da análise sobre algo que se pode nomear EXPERIÊNCIA COLETIVA PARTILHADA, acontecendo no espaço cotidiano da família como grupo social. Especificamente, focalizou-se a inserção da criança em um mundo social, mediante a identificação de alguns dos mecanismos culturalmente estruturados pelos quais a família promove a inclusão da criança como membro co-responsável por tarefas e decisões, partilhando afazeres, preocupações e decisões, ensaiando papéis ligados à sobrevivência, à organização coletiva da vida cotidiana, à produção e consumo de bens, e a projetos coletivos em curso no âmbito do grupo familiar. Este, o contexto de desenvolvimento do indivíduo, que não existe senão em interação com as diferentes instâncias desse "coletivo". Uma descrição do fenômeno que reconheça a tensão individual-coletivo exige um nivel de análise diferenciado, o que é muitas vezes um desafio:

"É crucial ver a familia como um sujeito coletivo, com seus processos internos de mediação e diferenciação e seu potencial assimétrico para poder e acesso a recursos, ... não apenas aqueles corporificados nos assim chamados recursos materiais, isto é, renda, serviços, redes de consumo, redes de relações. São, por natureza, também culturais e simbólicos". (Chiara SARACENO, 1989).

Propôs-se como hipótese que mudanças cruciais em padrões de organização e vida em família podem ser observadas nessa dimensão da responsabilidade em relação ao grupo familiar vs. individualismo. Nas famílias de camadas populares, seria mais forte uma ordem moral baseada na responsabilidade (modelo de identidade compar-

4. "Nesta maravilhosa manhã de primavera vejo através de uma janela uma azaléia em plena floração. Não, não! Isto não é o que vejo; mas é a única maneira pela qual posso descrever o que vejo” (C. Peirce, 1987, apud SAMAJA, 1993). 
tilhada, de que fala NICOLACI-DA-COSTA, 1989); nas camadas médias, o pólo individualista tenderia a crescer (modelo de identidade diferenciado).

Foram objeto de análise questões mais específicas, como: (a) frente às necessidades e circunstâncias que vão constituindo a trama do cotidiano familiar, que práticas são construídas em conjunto, que experiências são partilhadas por adultos e crianças? (b) De que maneiras idéias dos adultos sobre criação de filhos e organização do cotidiano se articulam com essas práticas, e com valores genéricos, presentes no contexto cultural imediato ou amplo? O que essas idéias informam sobre a estruturação cultural do contexto de desenvolvimento? (c) Através de que mecanismos a criança vai, ativa, responsável e progressivamente, e em um processo de modulação com o "outro social”, co-construindo modos de partilhar a experiência coletiva do primeiro grupo social do qual ela é membro?

Discutiu-se esse conjunto de questões tomando como referencial desenvolvimentos teóricos que privilegiam a questão da cultura, configurando um paradigma emergente para a Psicologia do Desenvolvimento (VALSINER, 1987; TOMASELLO, KRUGER \& RATNER, 1993). São partilhadas, portanto, as preocupações daqueles que, na Psicologia do Desenvolvimento, trabalham para compreender as complexas relações entre cultura e desenvolvimento, especialmente no terreno de uma psicologia de inspiração ecológica, sensível a influências presentes numa área de interseção entre psicologia e antropologia, onde se inserem trabalhos como o de GOODNOW e COLLINS (1990), particularmente quando f ocalizain a questão de idéias sobre criação de filhos e o caso do trabalho doméstico, e a proposta de uma psicologia do desenvolvimento inclusiva de cultura, que vem sendo recentemente nomeada semiótico-construtivista (SIMÃO, no prelo), constituída a partir da teoria sócio-histórica de L. VYGOTSKY (apud VALSINER, 1987) e tal como representada nos trabalhos de J. VALSINER(1987, 1989, 2001) e outros.

\section{Prática cultural como unidade de análise}

Para uma análise de processos de desenvolvimento dentro de uma área de significados formada por valores culturais dos pais e da família, descrita por VALSINER (com. pes., 1991) como "zone of meaning bounday", ou "zone of promoted ideas", focaliza-se o modo e a extensão em que esse espaço ideológico é conformado por circunstâncias ligadas à luta cotidiana para sobreviver.
O conceito de práticas culturais (GOODNOW, 1993) foi assumido como uma estratégia para identificar princípios através dos quais uma sociedade ou uma família operam: os chamados "modelos culturais subjacentes". Por um lado, aponta a possibilidade de descrever contextos de desenvolvimento em termos de práticas às quais aderem os membros de um grupo, em sua maioria, e em termos da forma peculiar pela qual novos membros vêm a participar de determinadas práticas. Por outro lado, fornecem um recurso para a descrição do processo de desemvolvimento, focalizando o envolvimento conjunto de indivíduos com diferentes experiências, significados e habilidades. É especialmente importante afirmar que é no contexto da vida cotidiana mais rotineira (envolvendo eventos corriqueiros: comer, dormir, limpeza pessoal, possuir objetos ou distribuir recursos) que essas práticas ocorrem, permitindo que interpretações do mundo e da vida social sejam veiculadas.

No plano empírico, essas questões levaram a uma pesquisa de corte longitudinal, concretizada em um estudo intensivo sobre dez famílias, ao longo de uma década. Foram gerados, a partir de múltiplos recursos (entrevistas, sobretudo, mas também observação, fotografia e vídeo), um material qualitativo extremamente rico e diversificado, cuja análise foi possível a partir da identificação da categoria modos de partilhar, tratada como unidade de análise central no estudo e capaz de descrever, para sete diferentes domínios da vida cotidiana do grupo familiar, práticas em que a criança se insere, idéias que acompanham essa inserção e sua natureza (tipo de participação).

Em paralelo à descrição geral da realidade das famílias, um dos principais resultados dessa investigação foi a descrição do processo que conduziu à identificação dos modos de partilhar e dos produtos gerados a partir dessa unidade de análise. Esses produtos foram objeto de um tratamento quantitativo simples, para facilitar a síntese dos dados, e de análises qualitativas, cuja finalidade era a de identificar a configuração assumida pelas relações entre o contexto cultural, a estruturação do contexto familiar, situando aqui as idéias parentais e a participação da criança.

\section{OS MODOS DE PARTILHAR}

A categoria modos de partilhar envolve descrições da experiência coletiva cotidiana da família, conduzidas de modo a incluir, em um mesmo olhar analítico: (a) uma dimensão comportamental: a amplitude de práticas em que as crianças se inserem; (b) uma dimensão cognitiva: as 
justificativas que os pais apresentam imediatamente a essa inclusão; (c) a avaliação dos pais quanto à frequência e ao tipo de participação da criança, considerados como descritores do contexto interativo no qual sua inclusão se dá.

Modos de partilhar, enquanto unidade de análise central no estudo é portanto uma categoria ampla, análoga ao conceito de nicho de desenvolvimento (SUPER \& HARKNESS, 1986). Sintetizam contingências no plano imediato ao evento que está sendo descrito e que atuariam simultaneamente com as contingências culturais mais amplas que estão dispostas para o grupo; na medida em que se busca uma integração de fenômenos que ocorrem em diferentes níveis de análise, esta unidade pode explorar o conceito de metacontingência proposta por GLENN (1988).

A unidade de análise, na estrutura lógica da matriz de dados, ocupa o lugar do argumento (SAMAJA, 1993). É o fenômeno sob estudo, substantivado aqui numa instância relacional: ações interligadas de diferentes membros do grupo familiar. Trata-se portanto de um nível de análise que vai além da ação individual: diz respeito às ações do outro em articulação com as ações da criança, em um segmento interativo, configurando modos de participação (GÓES, 1993). Expressam-se aqui convergências com a idéia de envolvinento conjunto proposta por SCHAFFER (1992; 1984) para caracterizar episódios de interação pais-filhos; com os mecanismos de modelação e aprendizagem vicariante estabelecidos no contexto da análise experimental do comportamento; e com a variada nomenclatura disponível para descrever a ação combinada de parceiros sociais, orientada por metas e gerando significados, dentro das orientações sócio-construtivistas de Jaan VALSINER, Barbara ROGOFF e Jacqueline (GOODNOW, entre outros ("ação partilhada”, “ajuda”, “estabelecimento de ponte”, “criação de estrutura de suporte”, 'scaffolding", "transferência de responsabilidade” ou "controle”, como sugere GOES, 1993).
A ênfase aqui não recai propriamente sobre a 'ação do outro', mas sobre as práticas nas quais crianças se envolvem, numa dimensão que é necessariamente coletiva, sendo a descrição desse envolvimento contextualizada por valores culturais presentes nas atribuições de justificativas parentais para sua inserção (ou exclusão). Apenas secundariamente a análise torna evidente $o$ contexto interativo pelo qual a criança se insere em práticas cotidianas em curso na família, quando classifica sua participação como complementar à do adulto ou autônoma; atribuída ou espontânea; com ou sem instruções; promovida ou inibida.

SAMAJA (1993) fala, ainda, de configurações de matrizes de dados; sua proposta de superar falsas dicotomias entre individual e coletivo mediante a noção de sistemas (e subsistemas) é bastante aplicável aos fenômenos aqui focalizados. Do mesmo modo a hierarquização de matrizes a partir de suas interrelações (coordenadas, subordinadas, supraordenadas). No Quadro 1, a seguir, os Modos de Partilhar, enquanto principal unidade de análise deste estudo, podem ser vistos dentro de uma configuração de matnzes.

Os modos de partilhar, enquanto unidade de análise, incluem elementos comportamentais e cognitivos, ao mesmo tempo em que identificam sete diferentes domínios da vida da família. Podemos considerar que esses domínios, enquanto âmbitos ou contextos nos quais a vida cotidiana da família se organiza, situam-se no nível supraunitário do sistema de matnzes. São eles:

1. Empreendimentos e iniciativas da Jamilia voltados para gerenciar receita (principal ou complementar);

2. Limpeza e arrumação da casa e cuidando a irmãos menores no âmbito da casa;

3. Preparo e distribuição de alimentos, e atividades relacionadas a estas (manusear fogão e utensílios, limpeza no âmbito da cozinha);

4. Cuidados com os próprios pertences e tarefas escolares;

Quadro 1. Os modos de partilhar dentro de um sistema de matrizes de dados.

\begin{tabular}{|l|l|l|l|l|}
\hline \multicolumn{1}{|c|}{ INDICADOR } & \multicolumn{1}{|c|}{ VALOR } & \multicolumn{1}{|c|}{ DIMENSÃO } & UNIDADE ANÁLISE & \multicolumn{1}{|l}{} \\
\hline $\begin{array}{l}\text { Narrativas } \\
\text { Observações }\end{array}$ & Classificação & Esferas do cotidiano & Contexto familiar & $\begin{array}{l}\text { Nivel supra- } \\
\text { unitário }\end{array}$ \\
\hline $\begin{array}{l}\text { Narrativas } \\
\text { Episódios } \\
\text { observados }\end{array}$ & Tipos de família & $\begin{array}{l}\text { Crenças; } \\
\text { Práticas Interação }\end{array}$ & $\begin{array}{l}\text { MODOS DE } \\
\text { PARTILHAR }\end{array}$ & $\begin{array}{l}\text { Nível de } \\
\text { ancoragem }\end{array}$ \\
\hline Narrativas & Padrões & Responsabilidade & $\begin{array}{l}\text { Participação da } \\
\text { criança }\end{array}$ & $\begin{array}{l}\text { Nivel sub- } \\
\text { unitário }\end{array}$ \\
\hline
\end{tabular}


5. Atividades extra-muros: fazer pequenas compras, dar recados, acompanhar irmãos menores e parentes idosos em incursões fora da casa;

6. Eventos intra-familiares (originados ao nível da dinâmica de relações interpessoais), conflitivos ou não, requerendo algum tipo de tomada de decisões e gerenciamento;

7. Eventos extra-familiares que afetem a forma usual de organização do cotidiano familiar (mudanças a nível do emprego, novos membros da família, visitas etc.)

Foram assumidas as seguintes definições para os componentes dos modos de partilhar:

As práticas relatadas ou observadas: a atividade da criança e as ações dos pais promovendo ou restringindo essa ação.

Justificativas parentais para a inserção da criança nestas práticas: justificativas imediatamente expressas no material transcrito, bem como ensaios de leitura e interpretação do transcrito, buscando identificar os princípios e relações contidos na prática. Classificam-se em cinco subcategorias: A. Centradas em necessidades/ circunstancias; B. Centradas em crenças sobre criança e desenvolvimento; C. Centradas em metas, objetivos pedagógicos, a médio e longo prazos: D. Centradas na condição de pertencer à família; E. Centradas na natureza da tarefa.

\section{$O$ contexto interativo}

Esta dimensão refere-se ao tipo de participação da criança na tarefa ou na situação focalizada. Classificado em cinco categorias, confonne competência na execução, compromisso com a tarefa, origem imediata da ação, ensino ou orientação para a tarefa e permissão para a ação, esse componente situa-se no nível subunitário do sistema de matrizes.

\section{RESULTADOS E DISCUSSÃO}

A utilização da categoria modos de partilhar permitiu discutir de forma articulada os planos semantico e comportamental do fenômeno em estudo (a inserção da criança como membro da família). É o que se expõe nesta seção.

\section{O sumário quantitativo}

Para obter uma visão global das práticas nas quais as crianças participaram, selecionamos alguns aspectos do material qualitativo para avaliação quantitativa, considerando o total de crianças $(n=25)$, estratificadas segundo a configuração familiar, a idade, o sexo e a posição da criança na farnília 5 .

guintes:

As dimensões quantificadas foram as se-

a. A diversidade ou amplitude das práticas. Trata-se de uma estimativa particular da freqüência, que mostra o número de práticas diferentes dentro de cada domínio do cotidiano familiar.

b. O total de crianças engajadas em certa prática, para cada domínio do cotidiano familiar.

c. O estilo de participação nas diversas práticas, para cada domínio, avaliado pelo adulto (pais, avós, parentes adultos, ou o próprio pesquisados, quando se tratava de episódios observados). Neste momento, duas sub-diinensões do contexto interativo (terceiro componente do modo de partilhar) eram focalizadas: o compromisso com a tarefa e a competência em sua execução.

d. A frequência de sub-categorias dejustificativas para a inserção da criança nas práticas em curso, para cada domínio considerado.

No Domínio 1, onde é um pouco menor a quantidade de práticas diferentes, e no qual se registra um dos menores percentuais de sujeitos envolvidos, há uma clara diferenciação de médias quando configuração familiar e posição na tàmília são critérios de estratificação do grupo. A participação da criança em atividades familiarcs voltadas para complementação de renda é de maior amplitude quando se trata do filho (ou filha) primogênito(a) e quando a família é do tipo extensivo.

Já no Domínio 2 - arrumação da casa e cuidado de irmãos - que concentra a maior variedade de práticas e onde ocorre o seu valor médio mais alto, são exibidas diferenças notáveis entre as quantidades médias de práticas diversas quando os sujeitos são agrupados por sexo e idade. Cabe às meninas e às crianças mais velhas participar em uma maior amplitude de práticas.

Quanto ao Dominio 3 - preparo e à distribuição de alimentos, encontram-se mais uma vez as condições de primogênito e de idade entre 7 e 13 anos como responsáveis pelas maiores diferenças entre as médias de tarefas diversas relatadas. É bem menor a diferença quando se agru-

5 Rotinas muito simples do SPSS, na versão 5.0.1 para Windows foram utilizadas na análise para extrair distribuições de frcqüências (frequencies e multiresponses), comparando-se proporções de sujeitos nas diferentes condições (crostabulations) e algumas médias das freqüências de práticas nas quais as crianças estiveram envolvidas (meams tables). Não se julgou apropriado calcular níveis de significância estatística. 
pam os sujeitos por sexo, embora os dados ainda mostrem o envolvimento de meninas em um maior número de práticas distintas.

O Dominio 4 - estudo e cuidado dos próprios pertences - encerram características especiais, uma vez que se trata de atividades voltadas para o interesse individual da criança. Entretanto, há dimensões destas atividades que se voltam claramente para o interesse do grupo familiar: desde requisitos de organização pessoal, da qual também depende o bem estar do grupo (especialmente quando o uso de um reduzido espaço é coletivo) até o cumprimento de um projeto coletivo familiar, como é o caso da escolarização dos filhos. Pode-se considerar, mesmo, que a maior parte das conseqüências do engajamento individual em estudo, higiene e organização de objetos pessoais são coletivas. A lógica dessa organização é coletiva; dificilmente uma criança compreenderá os princípios subjacentes à sequência em que tarefas devem ser feitas, à disposição em que objetos devem ser colocados; ela seguirá esses princípios para evitar as conseqüências aversivas e maximizar as reforçadoras.

O exame dos dados quanto ao Domínio 5 é interessante para caracterizar a relação casa rua e a gênese da exploração do mundo externo ao lar pela criança. Em primeiro lugar, as médias de práticas diferentes onde há o envolvimento de meninos e meninas aproximam-se mais que em outros domínios, sugerindo uma participação relativamente maior dos meninos quando se trata de idas fora de casa especialmente se mais velhos e primogênitos.

O Domínio 6 tem a singularidade de não envolver tarefas no mesmo sentido que os domínios anteriores. A zona de desenvolvimento em que a criança se movimenta, aqui, implica sua atuação frente a respostas emocionais e afetivas de outros; assim como outras pessoas numa família, também a criança avalia ações e emoções de outrem, comentando, criticando e tomando decisões, considerando, necessariamente, as possíveis conseqüências de sua ação. Quando o comportamento de uma criança passa a ser controlado por conseqüências que se colocam para todo um grupo, pode-se dizer que a criança está se tornando parte de uma cultura, dominando regras e valores culturais, adquirindo características e estilos de comportar-se que permitem aos demais identificála como pertencente a um grupo particular, a uma família.

O campo das relações interpessoais, marcado por conflitos, demonstrações de agressão e carinho, preferências, jogos de poder, é a área que atrai, por excelência, a atenção dos estudiosos da dinâmica familiar: este entrelaçamento entre as vidas de um e de outro; esta mistura de vidas que compõem a família, mais que os laços biológicos; estes pactos não consagrados, não escolhidos, estas redes de obrigações mútuas estabelecidas como material de solidariedade, opressão, ressentimentos, afetos. O processo de socialização é um todo organizado e coerente que as limitações da análise obriga a decompor em partes isoladas. Da mesma forma que ocorre em aspectos nos quais o desempenho adquire inaior evidência, havendo uma tarefa sendo executada e um produto publicamente aferível existem, pois, regras e expectativas, explícitas ou não, sinalizando o comportamento esperado, as ocasiões em que deve ocorrer e suas prováveis conseqüências.

$\mathrm{O}$ acesso ao tipo de dados aqui focalizados foi mais restrito, em comparação aos demais modos (dependia mais de observação do que de entrevista). Mesmo assim, a variedade de práticas e o percentual de crianças nelas envolvidas não se distanciaram dos demais. Repete-se a tendência geral no sentido de a média de participação em práticas diferentes ser maior para as meninas, as crianças mais velhas e, com especial ênfase, para os primogênitos. Como se verá logo adiante, o exame do material qualitativo converge fortemente neste mesmo sentido.

Quanto ao Dominio 7, no qual se focaliza a ação da criança frente a eventos de origem exterior que de alguma forma alterem a organização cotidiana da vida familiar, algumas das considerações feitas em relação ao Domínio 6 também se aplicam. As tendências observadas nos diferentes agrupamentos analisados é bastante similar às dos demais modos. Registra-se novamente o envolvimento em maior diversidade de práticas entre as meninas, as crianças de maior idade e os primogênitos.

Os dados discutidos acima documentam o quão extensa é a participação da criança como um membro atuante em diversas esferas da vida cotidiana do grupo familiar.

De um modo geral, as análises permitiram a sistematização de relações importantes, e foi possível assinalar a interdependência entre contexto cultural, idéias parentais e o engajamento da criança em práticas coletivas em curso na família. Dentre as principais conclusões, destacamos:

e. A sobrecarga de trabalho da mulher enquanto dimensão importante na estruturação da rotina familiar, incidindo diretamente sobre a extensão e a qualidade da participação da criança;

f. A dignificação do trabalho realizado no ambito da casa como principal estratégia pedagógica utilizada pelos pais na educação de seus filhos e afirmada, do ponto de vista dos pais, 
como estratégia apropriada para as classes inais pobres;

g. A indicação de que a inserção da criança nas diferentes esferas da vida familiar é muito expressiva, considerada quantitativamente, e muito extensa e diversificada, quanto à sua qualidade, não podendo ser compreendida de forma homogênea, mas como algo que se modifica segundo as características da criança, domínio do cotidiano em questão, e valores culturais estabelecidos, que imprimem rótulos sobre o que é socialmente apropriado e esperado dentro de diferentes condições;

h. Quando atribuindo tarefas às crianças, o comportamento dos adultos vai depender da complexidade de cada tarefa, havendo uma interação entre uma hierarquia dos significados dos diversos domínios do cotidiano, dentro da família (segundo o valor relativo às funções e aos recursos implicados) e os conceitos relativos ao que é socialmente conveniente para a criança;

i. No que concerne ao tipo de participação, os resultados sugerem uma concentração de crianças mais velhas, de primogénitos e de meninas, em torno de uma participação do tipo regular-autonomo, o que pode representar uma mudança com referência a uma participação inicialmente esporádica-complementar à ação do adulto;

j. Embora as justificativas parentais para promover ou restringir a participação da criança tenham estado centradas sobre finalidades pedagógicas, parece ocorrer aí uma distribuição diferenciada, sugerindo que o domínio da vida familiar em questão especifica os significados ou as justificativas para a participação da criança, provavelmente em conformidade com os valores culturais subsistentes no grupo social de referência.

\section{Modos de partilhar: as distintas qualidades}

Diferentes formas e significações emergem da descrição da participação da criança nos domínios da vida cotidiana aqui analisadas. Para apresentar sinteticamente os resultados mais importantes, nós escolhemos focalizar sobre os modos de partilhar em apenas dois dos sete domínios da vida cotidiana tomados em consideração neste estudo. Pretendemos inostrar a interligação de significados culturais e práticas que é possível encontrar nos episódios analisados. Trata-se agora das diferentes qualidades de participação nos modos de partilhar obser- vados dentro de um determinado domínio, do ponto de vista do conteúdo da prática e dos significados nela envolvidos.

\section{A PARTICIPAÇÃO DA CRIANÇA NOS EMPREENDIMENTOS FAMILIARES PARA GERAR RENDA}

No limiar da casa e da rua, entre os mundos privado e público, entre o aprendizado e a necessidade, a ação da criança é diretamente influenciada pela ação do adulto. Parece que, do ponto de vista dos pais, os constraints ou delimitadores (aquilo que limita e aquilo que permite) em torno da participação da criança são dependentes tanto dos recursos em jogo (recursos limitados e difíceis de obter, em termos do tempo e do trabalho exigidos) como da complexidade das tarefas a realizar. O trabalho que gera renda é, de uma forma muito clara, um assunto de adultos.

Quanto ao conteúdo, foram identificadas diversas formas de participação: o envolvimento direto na atividade (Roseane) ${ }^{6}$, o desempenho de outras tarefas no âmbito doméstico de forma a liberar a mãe para o trabalho remunerado externo ao lar (Júnior), a iniciação no aprendizado de um ofício pela observação "sistemática” do desempenho do adulto em situação de trabalho, incluindo trabalho externo ao lar (Roberto). Os fragmentos dos quadros de análise inseridos a seguir, no Quadro 2, ilustram essas diferenças. Observe-se que as justificativas apresentadas pelos adultos, sempre no sentido de promover o envolvimento da criança nas práticas, indicam quase sempre circunstâncias (categoria A) ou intenções e estratégias pedagógicas (categoria $\mathrm{C}$ ).

Neste modo de partilhar, a centralidade do trabalho como critério de organização de rotinas familiares, também observada por autores como BILAC (1978) e ARROYO (1991) em famílias brasileiras, apresenta-se muito clarainente. Assim, no que se refere a significados pedagógicos em torno do envolvimento da criança, nota-se como o valor atribuído a uma habilidade demonstrada pela criança depende diretamente do quanto esta habilidade possa ser revertida no sentido de produzir e carrear recursos para a família. Isto se evidencia em várias das famílias. Lourdes, frente às habilidades de Lázaro (16 anos) como pintor e escultor, comenta:

"Ele tem assim umas nesteiras de arte de fazer umas coisas de arte assim fazer al-

6 Os sujeitos estão identificados por pseudônimos. 
Quadro 2. Excertos dos quadros de análise exemplificando diferenças quanto ao conteúdo da participação da criança e das justificativas parentais, para o Domínio 1 .

\begin{tabular}{|c|c|c|}
\hline Justificativas & Categoria & Práticas Relatadas \\
\hline \multicolumn{3}{|l|}{ Roseane (9 anos) } \\
\hline $\begin{array}{l}\text { Avó temporariamente ausente } \\
\text { Ocupação como oportunidade de desempenhos } \\
\text { desejáveis e preferiveis ao estar na rua }\end{array}$ & $\begin{array}{l}\mathrm{A} \\
\mathrm{C}\end{array}$ & $\begin{array}{l}\text { Tomar conta da loja (atender fregueses) } \\
\text { Ajudar avó a atender fregueses } \\
\text { (perguntar à avó sobre preços; informar } \\
\text { preços a fregueses) }\end{array}$ \\
\hline \multicolumn{3}{|l|}{ Júnior (7 anos) } \\
\hline $\begin{array}{l}\text { Ausência da màe para vender produtos de beleza } \\
\text { (trabalho extra, complementar) }\end{array}$ & $\mathrm{A}$ & $\begin{array}{l}\text { Depositar dinheiro da mãe em uma } \\
\text { "caixa" (poupança informal entre } \\
\text { amigos) } \\
\text { Levar catálogos de produtos vendidos } \\
\text { pela mãe e divulgá-los na vizinhança } \\
\text { "Guardar" a casa na ausência da màe } \\
\text { (Manter o portão trancado; Guardar } \\
\text { cadeado e chave) }\end{array}$ \\
\hline \multicolumn{3}{|l|}{ Roberto (9 anos) } \\
\hline $\begin{array}{l}\text { Fornecer ocasiào para que R. observe o pai } \\
\text { trabalhando, como uma estratégia de ensino de } \\
\text { habilidades; } \\
\text { Prioridade a aprender desde pequeno um oficio } \\
\text { (estudo não parece tão relevante, mesmo na } \\
\text { infância); } \\
\text { R. só acompanha o pai "quando o serviço é perto"; } \\
\text { As ferramentas são caras e não podem ser perdidas } \\
\text { ou danificadas }\end{array}$ & $\begin{array}{l}\mathrm{A} \\
\mathrm{E}\end{array}$ & $\begin{array}{l}\text { Acompanhar o pai ao trabalho (Pegar } \\
\text { ferramentas indicadas pelo pai, à } \\
\text { medida em que o pai necessite) }\end{array}$ \\
\hline \multicolumn{3}{|l|}{ Tatiana (6 anos) } \\
\hline $\begin{array}{l}\text { Màe vende guloseimas para complementar a renda } \\
\text { Mãe ocupada com tarefas domésticas } \\
\text { Vigiar como proteção quanto a roubo por parte dos } \\
\text { próprios vizinhos }\end{array}$ & $\begin{array}{l}\text { A } \\
\text { A } \\
\text { A }\end{array}$ & $\begin{array}{l}\text { Ajudar a màe na venda de pipocas, } \\
\text { queimados e geladinhos, na janela da } \\
\text { casa (Vigiar os produtos; Ajudar a mãe } \\
\text { a botar preço nos queimados (escrever } \\
\text { preços: } 500,100 \text { ); Receber dinheiro dos } \\
\text { fregueses e entregar à màe }\end{array}$ \\
\hline
\end{tabular}

gumas coisas, pintar quadros. Eu espero que ele pelo menos faça alguma coisa que... se empregue em alguma coisa, né?” (Lourdes)

Habilidades emergentes devem pois ser imediatamente utilizadas para o trabalho e para gerar alguma renda, melhorando os "negócios" da família. Quando Ciane (9 anos) aprendeu a desenhar uns padrões florais, sua mãe passou a propor-lhe insistentemente que o desenho fosse aplicado em cerâmica ou em tecido. Habilidades cognitivas, como as compreendidas no manuseio do dinheiro, são particularmente destacadas; há uma idade em que se espera que esta aquisição ocorra (6, 7 anos). O exemplo de Tatiana é ilustrativo a este respeito.

Assim, a criança ainda é vista e valorizada por sua utilidade em termos econômicos, diferentemente da tendência apontada por ZELIZER (1985, apud GOODNOW, 1988); de onde não se pode concluir que o outro significado definidor da concepção contemporânea de criança (de valor inestimável, sentimentalizada), para esse autor, esteja ausente do contexto de famílias pobres. Numa sociedade complexa como a nossa, não apenas há uma variedade de práticas de criação de filhos, como documentado na literatura (NYE \& BERARDO, 1973), mas cada variedade é, por si mesma, múltipla o bastante para desafiar o esforço de compreensão. Certamente, mais de um tipo de justificativa comparece à atribuição de qualquer tarefa. Como em outros aspectos, aqui também se revela a multidimensionalidade do contexto de desenvolvimento (BRONFENBRENNER \& CROUTER, 1983; COLBY, 
1996), disponível para a criança, incluíndo a dimensão ideológica. Qualquer abordagem que ignore esta pluralidade (de resto, marca de pósmodernidade, dentro ou fora da esfera acadêmica e do mundo cultural dominante) estará fadada ao fracasso.

A explicitação de intenções e estratégias pedagógicas justificando a inserção da criança em determinada prática, do ponto de vista dos pais, envolve pois alguns significados diferentes. $\mathrm{O}$ primeiro deles, a iniciação no aprendizado de um ofício, é ilustrado por Lourenço, pai de Roberto. A transmissão oral de um saber ligado à educação - uma educação para o trabalho - é a referência para Lourenço: foi assim que ele aprendeu do próprio pai. Acredita que aprendeu porque "era interessado”, ficava olhando como o pai fazia; e conclui:

"Aprendi por curiosidade. Ói eu acho que deve saber de pequeno, porque eu me fiz com 16 anos".

Um outro significado de conotação pedagógica está presente na justificativa apresentada pela avó de Roseane: trata-se do engajamento no trabalho como alternativa à permanência da criança na rua, ociosa e exposta às "más companhias". Está presente aqui a preocupação quanto às características do contexto urbano imediato, tão forte entre as mães entrevistadas. De uma outra maneira, esta preocupação aparece também quando Tatiana toma conta dos itens que a mãe expõe à venda, na janela da casa, para evitar possíveis furtos por alguém da vizinhança. A vizinhança representa apoio social, é fonte de amizades, troca de favores, e por vezes ocasião de lazer; no entanto, é também via de acesso imediato a uma experiência de violência que a rua representa cotidianamente.

Outros significados são exemplificados pelo caso de Júnior: referem-se ao assumir a responsabilidade pela casa - tomar conta, ser o guardião da chave da casa, resolver todos os eventuais problemas, rotineiros ou circunstanciais - de modo que a mãe possa sair para o trabalho.

Por fim, um conteúdo presente em quase todos os exemplos, quanto às circunstâncias apontadas como ensejando o engajamento da criança nas práticas, neste modo de partilhar, é o objetivo de complementar uma renda insuficiente, como se vê nos casos de Júnior e Tatiana. É o plano da difícil luta para sobreviver que se configura nítido aqui, exigindo uma multiplicação dos esforços para carrear recursos, decididamente deslocando a mãe para a esfera do trabalho externo ao lar e alterando a organização do cotidiano.

\section{A PARTICIPAÇÃO DA CRIANÇA EM TAREFAS RELACIONADAS AO PREPARO E A DISTRIBUIÇÃO DE ALIMENTOS}

Na hierarquia das atividades cotidianas voltadas para assegurar a sobrevivência da família, a alimentação tem, sem dúvida, um lugar especial, por ser um item essencial e relativamente escasso. Quanto maior esta escassez, e menor o montante de recursos disponíveis para angariar alimentos, mais a sua distribuição estará sob o controle estrito da mãe. A esta compete maximizar os recursos e evitar qualquer desperdício. A explicação de uma das mães, abaixo, demonstra o quanto é difícil fazer com que a cesta básica, drasticamente reduzida, continue permitindo preparar o mesmo número de refeições (reduzindo quantidade e qualidade de alimentos em cada uma):

"Só a gente pra saber, porque senão, minha filha, o dinheiro não dá. A gente vai comprar um quilo, está mais caro, a gente tem que comprar meio e tem que dá, né isso?" (Dilza)

A passagem desta responsabilidade para as filhas é algo muito sério, e adiada o mais possível. Apenas em uma das famílias (a de Lourdes) a tarefa de cozinhar e servir as refeições estava sob a responsabilidade da filha de 18 anos. Mesmo em famílias como a de Sônia, onde suas irmãs adolescentes ( 13 e 17 anos) estão ativamentc engajadas no preparo das refeições principais (almoço e jantar - este, uma refeição leve, o "café da noite"), é a mãe quem, antes de sair para o trabalho, separa as porções de alimentos para aquele dia. Na maior parte dos casos, na hora das refeições? não é a criança quem faz o próprio prato. Por outro lado, é permitido à criança exercitar a aplicação de noções distributivas. tendo um acesso mais livre a alimentos que não são considerados essenciais.

Portanto, na atribuição de tarefas aqui, o lugar do alimento na hierarquia das prioridades domésticas, e sua evidente escassez, interagem com avaliações maternas quanto a competências específicas da criança. Essa avaliação de competências, como no Domínio 1, não segue um padrão linear de complexidade crescente, dado o valor do recurso envolvido - lá, dinhero; aqui, alimento.

A fàmília de Nivaldo exemplifica uma variação do padrão acima referido: há uma diferenciação, não só quanto ao tipo de tarefa na qual o engajamento da criança é favorecido, mas quanto a sexo e idade: o preparo do café da manhã passou a ser responsabilidade dos meninos, de 6 e 8 anos. $\mathrm{O}$ ensinar autonomia é aqui a justificativa mais importante (como de resto o é para as outras 
crianças do sexo masculino). Não por acaso, é esta a família com mais recursos financeiros.

$\mathrm{Na}$ ausência de maiores dificuldades do ponto de vista econômico, prevalece, pois, o princípio, freqüentemente enunciado (ver exemplo de Roseane), segundo o qual competência percebida deve ser exercida: se alguém já sabe fazer determinada tarefa, esta tarefa passa a estar sob sua rcsponsahilidade, completando requisitos para ser considerado membro da família em condições de crescente igualdade.

Dessa forma, a competência demonstrada pela criança na execução da tarefa parece ser, muitas vezes base suficientc para que o adulto lhe atribua tarefas, de forma que ela cumpra sua parte no atendimento das necessidades do grupo. Os episódios analisados documentam que esta atribuição não se dá sem negociações, envolvendo necessariamente, mudanças ao longo do tempo: à medida em que reavaliam a competência da criança, os pais reajustam seus critérios de atribuição de responsabilidades quanto à natureza da tarefa e ao compromisso com a mesma. Por sua vez as crianças farão suas próprias adaptações.

Quando a atribuição de tarefas passa a representar sobrecarga, a criança tende a se esquivar delas, envolvendo-se mais com brincadeiras e atividades de sua escolha individual. Um dos episódios analisados no caso de Roseane ilustra este padrão.

No preparo e distribuição de alimentos, a competência requerida é a do domínio de princípios de justiça distributiva, formulados cotidianamente para a criança em diversas situaçoes, mas para a qual não se reconhece estar pronta uma criança de 10 ou 11 anos. Esta crença liga-se diretamente à escassez de recursos; assim, só se encontra uma criança (de 12 anos ou menos) administrando preparo e distribuiçao de refeições principais quando não há outra alternativa, ou em situações de emergência como a exemplificada pelo caso de Roseane, que preparou refeições completas numa situaçao de crise familiar. No próprio discurso das mães, está dito explicitamente que essa interdição se deve, não à ausência de competência de lidar com panelas, retirar delas a comida, fazer um prato, mas à ausência de um domínio de noções de distribuição equitativa de recursos, particulannente em se tratando de recursos escassos:

"Eu deixo elas fazer as coisas no momento em que precise, ai, eu deixo... Agora, não precisando nuito prefiro fazer que aí eu sei como é que eu faço, gasto menos óleo, menos tudo e elas fazendo não sabe quanto custa. E no mercado também não deixo ir, porque eu acredito que só eu mesmo.” (Dilza)
Na percepção dos pais, há uma diferenciação quanto ao grau de “saber” necessário à execução de diferentes tipos de tarefas. Assim, requer-se um "saber” para "ensinar deverc.s”; é preciso "ser competente” para tal. Outras tarefas não são vistas como requerendo um "saber"; qualquer um pode executá-las, caso queira. Nem sempre essa percepção é redutível a um enunciado do tipo "quanto mais complexa a tarefa, mais competência é necessária”. O valor da tarefa, complexa ou não, para a família, também determina a quantidade de saber exigido: tarefas ligadas à alimentação, em especial, requerem maior “saber”, independentemente do nível de complexidade específico. Considerando essa relação competência-tarelà-significado da tarefa, há vários sistemas hierárquicos em jogo: ver o caso do cuidar de crianças, essa habilidade tão complexa e que costuma ser delegada a qualquer pessoa, quase sempre sem se considerar uma competência específica.

A restrição à participação da criança neste domínio, no que se refere diretamente ao preparo e distribuição de alimentos, leva em consideração, ainda, a natureza da tarefa (justificativa que se inclui na categoria $\mathrm{E}$ ), no que se refere aos instrumentos nela envolvidos: instrumentos cortantes, e, perigo maior, o fogão (tanto mais perigoso quanto menor o espaço físico). to” (Dilza)

"Menino bulir em fogão não da muito cer-

Em todas as famílias, este tipo de justificativa foi encontrado; na descrição de práticas efetivas, contudo, observou-se registro do manuseio do fogão (acender ou desligar o fogo) em muitas ocasiõ̃es, pela maior parte das crianças, incluindo crianças de 2 a 4 anos, como Ivan (filho de Neide) e Lia (filha de Maria Lúcia). Há uma iniciação, em um contexto lúdico onde a possibilidade de acender ou desligar o fogo é concedido pelas mães como privilégio altamente apreciado por crianças nesta idade. Tendo em vista o desenvolvimento de padrões comportamentais, podese perceber; a partir da comparação entre crianças de diferentes idades, uma evolução, na qual se sucederiam: (1) o manuseio do fogão com supervisão imediata do adulto, em contexto lúdico; (2) o manuseio eventual do fogão, diante de circunstâncias que impliquem o impedimento do adulto; (3) o manuseio do fogão para preparo de itens isolados - café, arroz; (4) o manuseio do fogão para preparo de uma refeição completa, sob a responsabilidade exclusiva da criança.

Como se pode apreender dos episódios citados no Quadro 2, a criança participa, sem restrições, em muitas das práticas incluídas neste domínio, através de um envolvimento tipicamente complementar à do adulto, e nas fases prepara- 
tória e conclusiva do modelo de "linha de montagem” que parece tão característico da confecção de alimentos na família. Esta linha de montagem seria uma variante da seqüência de múltiplas operações, exigindo atenção permanente dos executantes, observada por FERREIRA (1991), ao investigar rotinas domésticas em famílias similares às aqui estudadas. Todas as crianças estiveram envolvidas em algum momento desta linha de montagem: do cortar ou machucar temperos até o lavar pratos, limpar a mesa, partes do fogão (este tipo de manuseio é costumeiramente solicitado a crianças).

Esta "linha de montagem" mostra-se com clareza no episódio de preparação e consumo de um lanche pela família de Sônia, a partir da análise do registro em vídeo. A circunstância na qual esta linha de montagem está circunscrita é a sobrecarga de trabalho da inãe (uma mãe-gerente), cuja múltipla jornada de trabalho concilia as atividades como servente em uma escola particular, das 7 às $13 \mathrm{~h}$; de confecção e venda de bolos à tarde; o pré-preparo dos alimentos para que as filhas apenas terminem de cozinhá-los; o tomar conta do neto à tarde; a supervisão das tarefas domésticas e do andamento geral da casa. Rotineiramente, esta jornada estende-se até a ineianoite. Se os horários não são cumpridos, as conseqüências são bastante pesadas para a mãe - além de estender o horário de suas tarefas habituais, ela ainda tem que participar ela própria da arrumação da cozinha, para ininiinizar o atraso. A quebra dessa norma é, assim, uma falta grave, como se pôde apreender da intensidade da repreensão da consternação de Sônia e de sua irmã Andréa, e de como elas forain diligentes no fazer as tarefas de arrumar a cozinha e de preparar o lanche, tomando freqüentemente a iniciativa.

Os fragmentos apresentados exeinplificain, também, como diferentes argumentos ou critérios concorrem para justificar, do ponto de vista dos pais, a participação da criança em um único episódio (no exemplo, foram identificadas as categorias B, C, D e E). Deste ângulo - como de outros a partir dos quais se considera esta participação - fica evidente a multiplicidade de significados culturais em torno da participação da criança nos assuntos da família enquanto uma coletividade. Esses níveis de justificativas podem ser tomados enquanto vias de acesso às instâncias culturalmente estruturadas que constituem a malha das relações entre indivíduos e contextos de desenvolvimento, indicando contingências a serem descritas em diferentes níveis de análise (grupal e individual). Por fim, esta diversidade está longe de configurar um quadro estático, imutável: valores culturais são confrontados, e cons- tantemente renegociados, entre o indivíduo em desenvolvimento e seus parceiros sociais, dentro do grupo social de referência (ver Branco, 1993).

\section{Mudariças sócio-culturais e modos de partilhar}

Essa estratégia de análise, aplicada aos sete diferentes domínios da vida cotidiana da família aqui considerados, permitiu, portanto, caracterizar a educação a partir do trabalho enquanto eixo de socialização das crianças, especialmente quando a família é pobre. $\mathrm{O}$ aprendizado de um ofício e a valorização da experiência formal de educação, na escola, tinham um significado como projeto factível para as famílias na criação de seus filhos, e todas as iniciativas da família convergiam para sua garantia seja em atividades geradoras de renda, seja no âmbito da organização doméstica. Nessa seção final, observamos o quanto as mudanças sociais ocorridas durante o período em que transcorre o trabalho de campo alteram a continuidade dos projetos familiares de educação de filhos. Esse impacto pode ser visto de fonna muito clara considerando a situação particular do crescimento da violência urbana.

Para chegar a uma demonstração do quanto os modos de partilhar são sensíveis às mudanças que se passam na esfera social mais ampla, nós trazemos algumas observações feitas no período final de nossa inserção em campo (nono ano). São aspectos que nos colocarão diante da seguinte questão: será que a socialização pelo trabalho está perdendo terreno para a violência urbana? Caso sim, como isso altera os modos de partilhar no interior da família?

Observemos, de início, que o desenho longitudinal permite delinear mudanças tanto contextuais quanto pessoais. No interior dos modos de partilhar, é possível observar, ao mesmo tempo, mudanças de valores e significados, de contextos de interação pais-filhos, e das práticas nas quais as crianças (agora adolescentes) estão engajadas.

A violência urbana ocorre no contexto imediato às famílias, na maior parte dos bairros populares do Brasil de hoje. Seus efeitos incidem diretamente sobre os recursos de que dispõem os adolescentes para realizar tarefas desenvolvimentais apropriadas à sua idade, segundo os valores culturais prevalentes dentro de sua comunidade.

A violência urbana incide sobre o cotidiano dos adolescentes e de sua família porque implicam:

a) alterar as formas de assumir novos papéis na família. Lucas, aos nove anos, estando sozinho a tomar conta de sua casa, adotava a se- 
Quadro 3. Excertos dos quadros de análise exemplificando diferenças quanto ao conteúdo da participação da criança e das justificativas parentais, para o Domínio 3.

\begin{tabular}{|c|c|c|}
\hline Justificativas & Categoria & Práticas Relatadas \\
\hline \multicolumn{3}{|l|}{ Roseane (9 anos) } \\
\hline $\begin{array}{l}\text { Aceitaçào do caráter eventual da tarefa, por ser próprio à } \\
\text { criança fazer coisas só quando deseja. } \\
\text { A criança deve habituar-se a fazer bem feitas tarefas } \\
\text { adequadas à sua idade e competência }\end{array}$ & B & $\begin{array}{l}\text { Lavar e enxugar pratos, quando disposta, } \\
\text { mas sem deixar sujeira aparente }\end{array}$ \\
\hline $\begin{array}{l}\text { Noção de que a criança deve ser preservada de perigos } \\
\text { como os envolvidos no manusear o fogão }\end{array}$ & $\mathrm{E}$ & $\begin{array}{l}\text { É em geral impedida de manusear o fogào, } \\
\text { exceto se não há outra pessoa }\end{array}$ \\
\hline $\begin{array}{l}\text { Situação de emergência: mãe doente, avó viajando } \\
\text { Reavaliação de competências implicando em apresentar } \\
\text { exigências mais complexas, quanto à natureza da tarefa e } \\
\text { ao compromisso com a mesma }\end{array}$ & $\mathrm{A}$ & $\begin{array}{l}\text { Tomar conta da cozinha } \\
\text { - cozinhar um frango } \\
\text { - dar almoço aos irmãos }\end{array}$ \\
\hline \multicolumn{3}{|l|}{ Paula (11 anos) } \\
\hline $\begin{array}{l}\text { Irmà mais velha atribui as tarefas, objetivando dividir a } \\
\text { sobrecarga que recai sobre ela e reduzir duração da tarefa } \\
\text { Atribuição torna-se regular quando a irmã passa a } \\
\text { freqüentar um curso } \\
\text { Se a irmã sempre executou essas tarefas, P. também deve } \\
\text { executá-las } \\
\text { Adequação a sexo e a idade (espera-se maior } \\
\text { compromisso com a tarefa, em relação aos irmãos do } \\
\text { sexo masculino, que só devem limpar o que eles próprios } \\
\text { sujarem, fora dos horários regulares) }\end{array}$ & $\begin{array}{l}\text { E } \\
\text { D } \\
\text { A } \\
\text { B }\end{array}$ & $\begin{array}{l}\text { Lavar pratos eventualmente } \\
\text { Lavar pratos regularmente } \\
\text { Limpar a mesa de refeições } \\
\text { Limpar o fogão }\end{array}$ \\
\hline \multicolumn{3}{|l|}{ Sônia (11 anos) } \\
\hline $\begin{array}{l}\text { Princípio da divisão eqüitativa do trabalho (uma irmã } \\
\text { arruma a cozinha ao meio dia, a outra à noite) - não por } \\
\text { exigência da tarefa, mas por um principio de justiça } \\
\text { distributiva. } \\
\text { Há normas claras quanto ao horário em que uma tarefa } \\
\text { deve ser necessariamente realizada. Há como modelo } \\
\text { uma espécie de "linha de montagem": só com a cozinha } \\
\text { limpa será possível iniciar a confecção do bolo. } \\
\text { Estando a mãe presente, ela é a "natural" coordenadora } \\
\text { do trabalho, diminuindo a chance de a criança agir com } \\
\text { autonomia. Além disso, há uma diferenciação entre S. e a } \\
\text { irmà maior; cabe-lhe fazer tarefas complementares, } \\
\text { sempre com instruções verbais e modelos de } \\
\text { comportamento. Está implicito o reconhecimento de sua } \\
\text { condição de aprendiz, de menos responsável pela tarefa.. } \\
\text { Observa-se que a execução do trabalho doméstico (como } \\
\text { talvez toda execução de tarefas por parceiros habituais) } \\
\text { segue um modelo de "linha de montagem": a conclusão } \\
\text { de uma tarefa sinaliza o inicio da próxima, prescindindo- } \\
\text { se de instruções verbais. } \\
\text { Espera-se, no caso, que a criança aprenda uma seqüência } \\
\text { de operações a ser realizada na execução da tarefa X. } \\
\text { Espera-se também atenção constante. } \\
\text { Crianças não têm competência para assumir } \\
\text { responsabilidade por distribuir alimentos (evidenciando-se } \\
\text { a função central da alimentação); não dominariam noções } \\
\text { de distribuição adequadas. }\end{array}$ & py & $\begin{array}{l}\text { Lavar pratos diariamente ("a pulso"), apóso } \\
\text { almoço ou após o jantar } \\
\text { Arrumar a cozinha à noite } \\
\text { Fazer faxina no armário da cozinha } \\
\text { Limpar o fogão } \\
\text { É repreendida pela mãe por não ter } \\
\text { realizado a limpeza da cozinha no horário } \\
\text { determinado } \\
\text { Fazer tarefas complementares à da mãe } \\
\text { (trazer e entregar objetos à mãe, guardar } \\
\text { objetos em local indicado). } \\
\text { Permanecer atenta, observando a mãe } \\
\text { trabalhar; intervir no momento em que uma } \\
\text { ajuda é necessária. Muitas vezes esse } \\
\text { momento é discriminado por S. sem } \\
\text { qualquer instrução verbal da mãe. } \\
\text { Preparar sanduíches, após a mãe lhe } \\
\text { entregar bandeja, faca, e dar instruções } \\
\text { específicas, seguindo rigorosamente } \\
\text { instruções maternas. } \\
\text { Lanche é distribuido pela mãe }\end{array}$ \\
\hline
\end{tabular}


guinte forma de receber a pesquisadora, já conhecida, em sua casa:

"Quem é? Diga senão eu atiro".

b) modificar a composição dos vários níveis do contexto, criando e restringindo vias de passagem, rotas de escape, envolvendo desde o brincar ao aprendizado e exercício de conhecimentos e habilidades e configurando uma imobilidade em que a única saída é trancar-se no exíguo espaço das casas.

"O que eu acho perigoso assim, ir prá uma festa, um pagode, e rolar uma briga lá, eu já fico já ligado. Quem vai sobrar é a pessoa que não tem nada a ver; aí eu já fico já em parte, de lado, deixo...” (Wellington, 14 anos) "Tenho uma rixa com um menino lá. Eu não vou lá! Porque tá na área dele. Se eu chegar lá posso morrer. Agora se ele vem na minha área tem que matar logo ele. Sobre como se proteger. Me afastando. Que é o que Mainha fala: Ói os amigos que você anda... antes só do que mal acompanhado". (Wellington, 14 anos)

"Se brigar é revólver, porque é revólver, não pode passar naquela rua, e tal, isso é uma coisa muito chata " (Marcos, 17 anos)

"A minha escola tá parecenclo. sabe o que ela? O CAM. Ôxê, tudo fechaclo, negócio de presídio, menores, parece lá agora. As grade... Por fora tem duas camadas de, de... De ferro, tudo deste tamanho assim, ó. É medo. Do aluno escapar, né? Tem muitos que vai prá quadra...”. (Wellington, 14 anos).

c) criar referências de risco, que tendem a tornar-se ainda mais atrativas para o adolescente, considerando a fragilidade de suas figuras parentais e o despreparo de seus Professores. "Ele vendia a maconha deles por aí, manda as crianças vender. Vendem em troca de alguma coisa? Comprar arma. Comprar arma. Então esse seu amigo, ele fazia isso também? Fazia, só que minha mãe mandou eu parar de andar com ele. Quando eu parei, demorou uma semana e dois dias, o bicho morreu. E você já sabia disso: Sabia, mas...” (Lucas, 13 anos)

d) minar as crenças na efetividade de projetos de vida

"Eram mais fáceis as coisas, hoje é mais difícil. De você, por exemplo, sair e.saber... Principalmente desse lado, de.saher que horas vai sair mas não sabe se, que horas vai chegar, né? Antigamente não tinha isso. Também nesse lado de conseguir as coisas, escola.... Tem muita dificuldade”. (Marcos, ^17 anos)

"Se eu tiver um dos meus filhos fugindo da polícia, invadindo minha casa por causa de meus filhos pra matar, eu prefiro ver morto antes. Eu prefiro ver morto, porque eu acho que dói, viu. Dói! uma mãe trabalhando, ou um pai, e saber que o filho é maconheiro, o filho é assassino. E ela não tem sono pra dormir, não sente fome, só pensancio naquilo”. (Lourdes, mãe, 39 anos)

e) excluir pela estigmatização

"Você percebe a violência perto de você?" "Percebo, não, já vi a violênciu perto de mim. (...) Tem gente que tem medo de vir aqui no bairro. (...) diz que o pior lugar de Salvador é aqui”. (Wellington, 14 anos).

Se a violência se apresenta como uma entidade onipotente e paralisante, uma conseqüência será diminuir a condição de adolescentes e famílias de agir com iniciativa e protagonismo. "O maior risco qual é mesmo? Ficar por aí dando mole e os cara vir de lá dando tiro, sem saber onde é que vai pegar. Pega em qualquer um que tiver na firente. (...) Eu corro logo pra casa de alguém, primeira porta que eu ver aberta eu entro (...)", "Minha mãe não deixa eu ficar muito na rua de noite. Oito horus, sete horas ela manda eu entrar". (Lucas, 13 anos)

f ) Finalmente, a violência $\wedge$ din $\sim$ i $\sim$ ?ui a esperança.

\section{CONSIDERAÇÕES FINAIS}

A análise do cotidiano das fainílias a partir dos modos de partilhar permite a formulação de alguns principios gerais (regras culturais) que orientam a inserção da criança nas práticas de significação coletiva para a família enquanto unidade social. Esses princípios focalizam transformações observadas nas estruturas de interação social dentro da família, nas situações de trabalho ou como uma resposta à violencia urbana.

Amplamente considerados, esses princípios contribuem para afirmar a interdependência entre o desenvolvimento dos contextos e o desenvolvimento dos indivíduos. O contexto de desenvolvimento é multidimensional e comporta diferentes instaâcias e inter-relações. É possível que a descrição de práticas culturais possa representar uma abordagem empírica alternativa mais favorável a atingir a natureza processual do desenvolvimento-em-contexto. 


\begin{abstract}
This study aimed at identifying some of the culturally structured mechanisms through which the child increasingly participates in family life and becomes a co-responsible member, when developing activities connected with the collective organization of daily life. The authors emphasized not only the context of interactions in which this insertion is promoted, but also the parents' ideas on children upbringing, both in the more generic plane and in the immediate plane of family routine description, justifying the child's engagement. The cultural values expressed by the parents' justifications, promoting or restraining the child's participation, are important $\mathrm{dh} \wedge \mathrm{l} \sim$ ensions of the developmental context. The decisions made throughout this study were guided by culture-inclusive, ecology-inspired and semiotic-constructivist ideas. In the empirical plane, these questions led to an intensive study of ten families, during one decade. The analysis, which points to the interdependence between context, parents' ideas and child engagement, was possible after the identification of the category s $\wedge$ ZZari $\sim \wedge$ lg modes, taken as the unit of analysis and extracted from the analysis of the ongoing cultural practices in the family's daily life. The sharing modes can describe the types, qualities and nature of the relationship between parents' ideas and child upbringing practices, and also the cultural values prevailing in the reference cultural group. The analyses showed the interdependence between educational practices and cultural context, which is realized in various instances, interconnected in a fluid, reciprocal, non-linear way. The sharing modes express the coordination between different orders of external constraints and the action of the caretakers and ofthe child itself. In the article's conclusion, two examples ofthis interdependence are discussed.
\end{abstract}

Key-words: development-in-context; parent's conceptions; child participation; "modes of cosharing”.

\section{REFERÊNCIAS BIBLIOGRÁFICAS}

ARROYO, M. G. Revendo os vínculos entre trabalho e educação: elementos materiais da formação humana. In: SILVA, T. T. d. (Org.). Trabalho, educação e prática social. Porto Alegre, Artes Médicas, 1991.

AQUINO, J. G. Prefácio. In: LEWIS, M. Alterando o destino. Por que o passado não prediz o futuro. Campinas, Editora da Unicamp/Editora Moderna,1991.

BILAC, E. D. Famílias de trahalhadores. estratégias de sobrevivencia. A organização da vida familiar em uma cidade paulista. São Paulo, Edição Símbolo,1978.

BRANCO, A. U. Sociogênese e canalização cultural: contribuições à análise do contexto das salas de aula. Temas em Psicologia, 3: 9-17, 1993.

BRONFENBRENNER, U.; CROUTER, A. C. The evolution of environmental models in developmental research. In: MUSSEN, RH. (Ed.). Handbook of child psvchology. KESSEN,W. (vol. ed.). History, theory and methods. (vol. 1). New York, John Wiley \& Sons, 1983.

COLBY, A. The multiple contexts of human development. In: JESSOR, R.; COLBY A.; SHWEDER, R. A. (Eds.). Ethnography and human development. Chicago / Londres, The University of Chicago Press, 1996. (Cap. 15, p. 327-338).
FERREIRA, E. A. R. Irmãos que cuidam de irmãos na ausência dos pais: um estudo sobre desempenho em tarefas domésticas e interaçao entre irmãos. Brasilia, 1991. [Dissertação de Mestrado Instituto de Psicologia, Universidade de Brasília].

GLENN, S. S. Contingencies and meta contingencies: toward a synthesis of behavior analysis and cultural materialism. The Behavior Analyst, 11: 161179,1988.

GÓES, M. C. R. d. Os modos de participação do outro nos processos de significação do sujeito. Temas em Psicologia, 1: 1-5,1993. (N. temático: Desenvolvimento cogmitivo: linguagem e aprendizagem).

GOODNOW, J. J. Cultural practices: contributions and questions from the study of household tasks. In: SRCD Meeting, New Orleans, 1993. Comunicação apresentada ao simpósio Cultural practices as contexts for development: concept and research use. New Orleans Society for Research in Child Development - SRCD,1993. (mimeo).

GOODNOW, J. J.; COLLINS, W. A. Development according to parents. The nature, sources, and consequences of parents' ideas. Hove, UK, Lawrence Erlbaum Associates, Publishers, 1990.

GOODNOW, J. J. Parents' ideas, actions, and feelings: models and methods from developmental and social psychology. Child Development, 59: 286-320, 1988. 
HARRÉ, R.; GILLETT, G. A mente discursiva. os avanços na ciência cognitiva. Porto Alegre, Artes Médicas, 1994.

HOROWITZ, F. Exploring developmental theories. toward a structural/behavioral model of development. Hillsdale, New Jersey, Lawrence Erlbaum Associates Publishers, 1987.

LIGHTFOOT, C.; FOLDS-BENNETT, T. Description and explanation in developmental research: separate agendas. In: ASENDORPF, J. B.; VASINER, J. Stability and change in development. a study of methodological reasoning. New Bury Park, Ca, Sage Publications, 1992. Cap. 7, p. 207-239.

NICOLACI-DA-COSTA, A. M. Repensando a psicologia clínica. Psicologia: Teoria e Pesquisa, 5(1): 85-98, 1989.

NYE, El.; BERARDO, F. M. The family its structure and interaction. New York, Macmillan Publishing Co. Inc. / London, Collier Macmillan Publishers, 1973.

ROGOFF, B. Apprenticeship in thinking. New York, Oxford University Press, 1990.

SAMAJA, J. Epistemologia y metodología: elementos para una teoria de la investigación científica. Buenos Aires, Eudeba S.E.M, 1993.

SARACENO, C. The concept of family strategy and its application to the family-work complex: some theoretical and methodological problems. In: BOH, K.; SGRI11A, G; SUSSMAN, M. B. (Eds.). Cross-cultural perspectives on families, work and chamge. New York, The Haworth Press Inc, 1989. p. 1- 18.

SCHAFFER, H. R. Joint involvement episodes as context for development. In: MCGURK, $\mathrm{H}$. (Ed.). Childhood social development. contemporary perspectives. Yorkshire, Lawrence Erlbaum Associates Ltd., 1992.
SCHAFFER, H. R. The child's entry in a social world. London, Academic Press, 1984.

SCHAFFER, H. R. Joint involvement episodes as context for development. In: MCGURK, H. (Ed.) Childhood social a development. contemporary perspectives. Yorkshire, Lawrence Erlbaum Associates Ltd., 1992.

SIMÃO, L. M. Semiose e diálogo: para onde aponta o construtivismo semiótico-cultural? (mimeo: no prelo).

SKINNER. B. F. Can psychology be a science of mind? American Psychologist, 4 (11): 12061207, 1990.

SPINK, M. J. (Org.). Práticas discursivas e produção de sentidos no cotidiano. aproximaões teóricas e metodológicas. São Paulo, Cortez Editora, 1999.

SUPER, C.M.; HARKNESS, S. The developmental niche: a conceptualization at the interface of child and culture. International Journal of Behavioral Development, 9: 545569, 1986.

TOMASELLO, M.; KRUGER, A. C.; RATNER, H. H. Cultural learning. Behavioral and brain scientes. 16: 495-552, 1993.

VALSINER, J. Culture and the development of childrens action. a cultural-historical theory of developmental psychology. Chichester, John Wiley \& Sons, 1987.

VALSINER, J. How can developmental psychology become "culture-inclusive”? In: VALSINER, J. (Ed.). Child development in culture context. Toronto, Hogrefe and Huber Publishers, 1989.

VALSINER, J. Niches of cultural embeddedness. In: Comparative study of human cultural development. Madrid, Fundación Infancia y Aprendizaje, 2001. Cap. 4, p.77-98.

Recebido em 04/09/2003

Modificado em 20/09/2003

Aprovado em 30/09/2003 